\title{
Stephane Guégan, Théophile Gautier
}

\section{Annalisa Bottacin}

\section{(2) OpenEdition}

\section{Journals}

\section{Edizione digitale}

URL: https://journals.openedition.org/studifrancesi/4744

DOI: $10.4000 /$ studifrancesi.4744

ISSN: 2421-5856

\section{Editore}

Rosenberg \& Sellier

\section{Edizione cartacea}

Data di pubblicazione: 1 avril 2012

Paginazione: 170

ISSN: 0039-2944

\section{Notizia bibliografica digitale}

Annalisa Bottacin, «Stephane Guégan, Théophile Gautier», Studi Francesi [Online], 166 (I | LVI) | 2012

online dal 30 novembre 2015, consultato il 19 novembre 2021. URL: http://journals.openedition.org/ studifrancesi/4744 ; DOI: https://doi.org/10.4000/studifrancesi.4744

\section{Questo documento è stato generato automaticamente il 19 novembre 2021.}

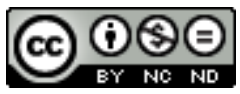

Studi Francesi è distribuita con Licenza Creative Commons Attribuzione - Non commerciale - Non opere derivate 4.0 Internazionale. 


\title{
Stephane Guégan, Théophile Gautier
}

\author{
Annalisa Bottacin
}

\section{NOTIZIA}

STEPHANE GUÉGAN, Théophile Gautier, Paris, Gallimard, 2011, pp. 700, ill.

1 Questo denso, erudito e prezioso volume biografico dedicato a Théophile Gautier non poteva trovare occasione più favorevole per la sua pubblicazione: è infatti nel 2011 che viene a celebrarsi il bicentenario della nascita «de l'homme au gilet rouge» della battaglia d'Hernani, come questo écrivain-voyageur viene per lo più ricordato dalla memoria collettiva.

Grande specialista del romanticismo francese, Stéphane GUÉGAN non è nuovo a studi e ricerche sui rapporti tra pittura e letteratura. Tra i molti volumi, cataloghi di mostre e articoli, ci è gradito ricordare l'eccellente lavoro dedicato a Stendhal scrittore d'arte (Salons), e pubblicato dal medesimo editore nel 2002. Il volume si articola in undici parti ed è corredato da un gran numero di rilevanti note; adottando una strategia dalla grande funzionalità, l'autore trascina subito il lettore in piena battaglia romantica che Gautier narrerà nell'Histoire $d u$ Romantisme, opera durante la cui redazione fu sopraffatto dalla morte; quella bataille d'Hernani, condotta alla Comédie-Française che lo vide tra i protagonisti con Gérard de Nerval e Pétrus Borel (legame che lo condurrà inevitabilmente a Novalis e a Hoffmann), di una rivoluzione che nel 1830 portò al trionfo il dramma romantico e che avrebbe avuto precisi strascichi anche in campo politico. (Gilet rouge et cheveux longs, pp. 11-62).

L'esegesi di Guégan mette a nudo sin dall'inizio quei congegni che producono l'effetto che il lettore attende da una biografia. In altre parole viene pian piano a emergere, con il tratto sempre riconoscibile di chi non solo interpreta bensì provoca l'avvenimento, operazione in cui Guégan sempre eccelle, i primi dati biografici della sua famiglia, dal nonno paterno Jean-Antoine Gautier «natif d'Avançon près de Gap ouvrier en soie» (p.14), ai genitori, allo spostamento della famiglia da Tarbes a Parigi, agli studi, alla 
predisposizione del giovane per la scrittura e la pittura, che è anche sguardo attento alle novità dell'arte romantica.

4 Ogni notizia relativa a Gautier, altra peculiarità di questo lavoro, è trasmessa sempre puntuale, e coincide, come dev'essere, con eventi socio-letterari che esaltano il valore intrinseco dell'uomo e dell'artista, talvolta anche investiti di un carattere assolutamente inatteso (Le bohémien du Louvre, pp.63-113). Ad appena vent'anni, inneggiante a Hugo e al suo dramma, Théo inizia con Victor Hugo un'amicizia e un «culto»; come Hugo sarà anche pittore, allievo di Rioult, ma la lettura delle Orientales lo conduce sulla strada della poesia. Già nel 1830 pubblica i primi versi nell'esaltazione della Beauté in ogni sua forma, cultore di una 'Religione del Bello', che sarà il suo credo dominante. A partire dal 1836 Gaurier inizia, non sempre entusiasta, la professione di giornalista e di reporter; scrive per «La Presse» e per «L'Artiste» lasciando pagine esemplari sulla sua epoca; viaggerà a lungo fornendo al pubblico suggestivi feuilletons che entusiasmarono i lettori. Non è certo da tralasciare il suo ruolo in campo musicale con gli originali testi per balletti e le sue critiche coreografiche, (e rimando in tema al volume di François BRUNET, Théophile Gautier et la danse). Figura poliedrica, fu dotato di grande sensibilità che lo porterà a essere un grande critico d'arte (segnalo a questo proposito Le Musée du Louvre de Théophile Gautier, a cura di Marie-Hélène GIRARD, che Gautier aveva redatto per l'Exposition Universelle del 1867, uscito per il bicentenario). Nelle sue relazioni di viaggio vi è un continuo richiamo all'estetica; rimangono esemplari le pagine dedicate alle bellezze artistiche di Venezia nel Voyage en Italie. Altra parte fondamentale del volume è quella dedicata alle donne amate da Gautier, che ebbero un ruolo fondamentale nella sua vita d'artista.

5 Nella biografia di Guégan anche i titoli dei capitoli sono depositari dei criteri adottati dall'autore, che intende fare circolare la figura di Gautier, che ha legato il suo nome ai più straordinari avvenimenti del xIX secolo, sotto l'impulso di una riflessione che riconnette la démarche gautieriana a una situazione più allargata, e che malgrado la centralità tematica si sposta su un panorama più generale e più ampio che investe appieno gli anni in cui Gautier visse.

Il volume è altresì corredato da un apparato iconografico assai rilevante, che risponde nell'immaginario gautieriano ad alcune forme nascoste che lo scrittore ha prodotto e organizzato nella costruzione di percorsi che, meglio e in modo nuovo, ci invitano a «pénétrer dans l'intimité d'un homme qui redoutait plus que tout la solitude et la chasteté». Un testo dunque da leggere e da meditare che si impone nella recente diffusione di studi e di opere di Gautier, ripresentate al pubblico dopo anni di immotivato silenzio. 